\title{
The museum between education and entertainment: The role of the museum according to the target public
}

\begin{abstract}
While at their beginning as cultural institutions the role of museums was to raise the public's level of education and culture, nowadays their role has become more diversified. Russel Berman speaks about the "de-sublimation" of the art, which is opposed to the vision of art for the sake of art, with a high emphasis on the public it addresses. In this context, the focus is changed from the creator/producer (including cultural institutions) to the public/consumer and to the relation between the artist and his/her public. In the contemporary society the museum begins to lose its sacredspace aura, gradually entering the everyday life and belonging more and more to the community which it is a part of and to which it addresses. In this approach, the museum may assume the social responsibility idea and respond to the needs of curiosity, entertainment and sharing the same identity and values and it may act as agent of social change as well, without betraying its role of public education and cultural values promotion. Which is the role of the museum institutions in this context? How do the museums reflect the contemporary Romanian society? How are the museums adapted to the public expectations? What is the loyal public of the museums? The paper intends to answer these questions about the role of museums in the Romanian society and to depict the profile of the current and potential public of the museums. In the Romanian society the museum is still the locus of the collective memory and the reflection of the identity and community and therefore it is dependent on its public. The public differs according to the museum's specific features and the structure of the public depends on various factors such as age, education level and access to the museum infrastructure.
\end{abstract}

Keywords: museums, public profile, cultural capital, habitus
Volume 2 Issue 3 - 2018

\author{
Anda Becuț Marinescu \\ Department of Research, National Institute for Research and \\ Cultural Training, Romania
}

\section{Correspondence: Anda Becuț Marinescu, National Institute} for Research and Cultural Training, 22 Bd. Unirii, Bucharest, Romania, Email andabecut@yahoo.com

Received: December 06, 2017 | Published: May 25, 2018

\section{Introduction}

The transition from a traditional society to a production and consumption-based society has transformed the manner one reports to artistic works, to the artist's condition and the definition of culture and its mission. Thus, we are assisting to the change and diversification of the production means and distribution channels of artistic creations. The democratisation of culture and the dissemination of the artistic works on mass level have led to the occurrence of the distinction between the elitist culture (specific to a certain social category) and the mass culture (an effect of the industrialisation of the cultural production and the emergence of creative and cultural industries). Scott Lash considers that the post-modern culture is characterised by what he calls "the aura eclipse", while Russel Berman speaks about art's "de-sublimation", which opposes the view of art for art's sake, through the greater emphasis on its target public. ${ }^{1}$ In this context, the emphasis moves from creator and producer (including cultural institutions) towards the public/ consumer and the relationship between the artist and the recipient of his/her creations. While initially the museums' role was to collect, protect, preserve and present to the public rare, beautiful, old objects, with heritage value, nowadays the role of museums is much more diversified.

In a post-modern, post-industrial consumption society, museums are passing through a process of reconfiguration of their role, which is not limited anymore to conservation/preservation, but combines education with leisure and social responsibility. Being a place of museums in the sense of the Greek word museion, according to the Encyclopaedia Britannica, the museum is still keeping its main role of cultural heritage conservation and protection, yet it begins to place itself at the crossroads between art and society. Thus, museums are becoming part of the non-formal life-long education system and address a diversified public. Regardless of their specific profile and the theme they approach, their educational mission is strengthened by the contemplative, reflexive and intellectualising dimension that they used to have during the Renaissance and the Enlightenment and that is still kept within contemporary museums by means of returning to curiosity and encouraging the public's creativity.

In the post-modern society, museums are landmarks of the local community, creative products used in local development strategies, important tourist attractions, contributors to the local economy, cultural production and consumption spaces, catalysts for investments and commercial spaces. In a consumerist society, museums are becoming cathedrals of consumption as defined by Ritzer, ${ }^{2}$ cultural malls as defined by Baudrillard, ${ }^{3}$ or "entertainment machines", ${ }^{4}$ meant to satisfy rather the appetite for playing and consumption than the need for knowledge. While the critics of museums having the main mission of preserving and protecting the heritage object to their indifference towards the public, a certain rigidity towards the social changes that do not reflect into the approaches of organising the exhibitions, or even the replication of a system of social exclusion and reinforcement of stereotypes, the critics of contemporary museums emphasise the consumerist, superficial and populist character of the new approaches 
in organising the exhibitions.

Thus, the studies on museums (particularly those on conservative museums) have shown that they reflect and strengthen the differences between social classes. According to Bourdieu, ${ }^{5}$ the behaviour of visiting museums is part of the social exclusion and distinction system, as it involves a certain educational, financial, social and cultural capital. Not even their presentation as heritage objectives, nor the free access can compensate for their image as places meant only for those who have the abilities of decoding the exhibition message and who are, most of the time, a rather limited group of persons with higher education, belonging to a certain category of age, to an ethnic or racial majority, with a certain level of income. In Bourdieu's approach, ${ }^{6}$ a certain economic and cultural capital is required in order to understand the art works or the exhibition message, while the habit of visiting museums is explained through the concepts of habitus and lifestyle, where education and family-model replication have a significant role.

As if governed by Janus, museums are depositories of memory, promoters of identity, educational and knowledge-acquiring instruments, yet in the meanwhile they are also intellectual enclaves, social exclusion and distinction instruments, promoters of divisions and symbolic legitimisation. This is why museums' role and mission of preservation and education have begun to be debated and criticised in the post-modern period, and the trend is to promote a more inclusive, less elitist museum, self-reflexive and mirroring the community of which it is part of. Sometimes the very argument of educating and raising the cultural level of the masses was used to support the need to find solutions adapted to draw categories of public-previously ignored by the curators-towards museums. Ironically, the term curator comes from the Latin curare, which means "to take care of", but the care only materialised as far as the exhibits-not the public-were concerned. ${ }^{7} \mathrm{~A}$ solution to diversify the public and to get closer to social, ethnical or generation categories, previously non-existent within the museums, was proposed by anthropologist Margaret Mead, who recommended that museums should develop familiar spaces (restaurants, shops), in order for these categories of visitors to get used to the museum space and to feel comfortable within an environment which otherwise they perceive as being completely alien (Ibid.p.32) This piece of advice has been followed in the last period by many museum managers and therefore we are assisting to the entrance of museums into the daily life and into the community they belong and address to. The image of museums as representatives of the elitist taste and institutional power is often incomplete and it sometimes contradicts the objectives and missions declared by the museum representatives, and occasionally even the concrete actions that take place within the museums, too. ${ }^{8}$

The relationship between the museum and its public has evolved from complete ignorance to subordination of the museum activity according to the public's expectations. When the museums first appeared, they were placed in a position which was superior over the public, their role being to raise the public's level of understanding, to elevate the visitors' spirit and taste. ${ }^{9}$ But in the last 40-50 years, this relationship has changed, and the public occupies now a higher position (Ibid). However, as the museum is being put to the public's and local community's service, the temptation to slip into excessive commercialisation and populism is big, and the boundary between sublime and ridicule is getting very thin. Thus, museums are in danger of turning from places of aesthetic contemplation into entertainment places ${ }^{4}$ from oases of tranquillity into noisy, crowded places, from promoters of education into fast-information places, from temples of heritage and knowledge into bazaars of cultural consumption. In an age of Internet and social networks, of cultural consumption fast-food type, of buzz-type (jingling) culture, the aesthetic contemplation gives way to the sensorial experience, and museums gradually become sensescape-type spaces where new technologies help visitors to get acquainted to the exhibits not only visually, but also by means of all their senses, in order for them to have a complete experience of the visit. The critics of the new trends in exhibition methods consider that, in their rush for visitors and (public and private) financing sources, museum managers and curators have compromised the quality and promoted a mass culture. This is why the necessity to have an in-depth knowledge of the public occurred, as in a globalised world, where cultural tourism brings another type of visitor-different from the local one-to museums, it is considered that we cannot speak about a public, but about many categories of public. This is how the proceedings to research and know the visitors' profile have started: who are they, how do they think, what do they feel, which is their relationship with the museum? Museums have started to become more reflexive in relation to their mission, their marketing strategies and their organisational policy. Exhibition themes have started being more and more connected to the public agenda and to the themes of actuality: gender differences, cultural diversity, environment awareness, the role of the artist in the contemporary society, social inclusion of persons with special needs, discrimination, political censorship, terrorism. All these themes have transformed the previous role of the museums as passive witnesses or, at best, as mirror of social changes, into an agent or even into an avant-garde of social changes.

In this context of redefining the role of the contemporary museums, the key question that rises is related to the role of museums in the contemporary Romanian society. Is it rather a role of conservation/ preservation of the museum exhibits? Or is it a role of cultural education, where the museum's offer is deemed to raise the cultural level and implicitly change the public's taste? Or is it rather a role of entertainment and in this case the offer must satisfy the public's need for spending their spare time and, implicitly, adapt to the public's taste? Can we speak- in the case of Romanian museums-of responsibility and social inclusion, in the sense that the museum's offer reflects social changes and/or acts as an agent of social changes? We shall try to answer these questions hereunder, through a case study based on the most representative museums in Bucharest, starting from the statistical data analysis by means of presenting the general situation of the analysed museums and studying thoroughly the results through an analysis of the visitors' profile, based on the data of the 2008 Cultura Consumption Barometer, following the thread through a virtual foray into the museum spaces.

\section{Materials and methods}

Our analysis is based on data from the Cultural Consumption Barometer (editions 2008, 2014 and 2016), ${ }^{10}$ which is a survey carried out at national level by a research center subordinated to the Romanian Ministry of Culture. The sample size was 1432 persons, with an error of $\pm 3 \%$, at a confidence level of $95 \%$. The sample contained a boost of 433 persons from Bucharest, which produced a sub-sample representative for the capital, with an error of $\pm 5 \%$ at a confidence level of $95 \%$. The national sample was three-staged, with stratification, first on development regions, followed by a random selection of the counties. In the second stage we applied a stratification on the size of the locality (cities, towns, villages, commune centres 
and peripheral villages), and a random-route selection was made. The number of persons from a certain locality was proportional with the size of the locality and the statistical weight of that type of locality in the respective county. Our analysis is based also on the information available in 2016 on the official websites of the analysed museums that refer to: the conservation, restoration and research dimension, the virtual tour, access to the museum and existing leisure spaces, educational programmes, cultural events, English version of the website. We chose to analyse these pieces of information because they are the potential visitors' first contact with the museum. Starting from the assertions in the previous section, we may consider that there are two types of museums: the conservative museum type-which has as main objectives the conservation and protection of the heritage and which assumes the education of the public as part of its missionand the post-modern museum type-which has as main objective the satisfaction of the visitors' need to spend their free time and which is adapting to the public's taste as far as the educational programmes are concerned, inclusively.

\section{Results and discussion}

The gradually increasing interest in the public and the need to know the visitors' profile led to the development of the research in the field and to the application of social theories in order to explain the visiting behaviour, the socio-demographical characteristics, the cultural, financial and social capital of the visitors. From the sociological viewpoint, museum visiting is considered rather a restrictive social phenomenon than a mass phenomenon. ${ }^{4}$ As a matter of fact, studies have shown that the socio-economic profile of the cultural consumers has changed very little in the last period, and this is why the studies have focused more on the interpretations and meanings given to the museum both by the visitors and by non-visitors. As we previously stated, we cannot speak about a public anymore, but about several categories of public, each type of museum having two types of public, a captive or regular type and a potential public type. The two types of public are defined or pre-defined by the role and mission the museum assumes to play within a community or society, in a certain period of time, and they may change according to the managerial policy and social changes. This is why it is important to follow the publicmuseum relation, according to the specificity of the museum, its role and mission and the public's profile. According to the data from the Cultural Consumption Barometer, available at national level, most of the respondents $(69.5 \%$ in 2008 and $62 \%$ in 2016) have never visited a museum in the last 12 months.

The low level of visits in Romanian museums might be explained by how they are perceived, by the people's preferences in terms of museum exhibitions and by the way of communication in online environement. In Bucharest, in 2008 the first in the museums top of preferences was the Village Museum, followed by Antipa Museum, Peasant's Museum and the National History Museum, while in 2014 the Antipa Museum was on the first place, folowed by the Peasant's Museum and the National History Museum. ${ }^{10}$

In 2008 the majority of the visitors, regardless of the museum type, were women with middle and high education, and the age category varied according to the museum type. As far as the relation between the visiting behaviour and the gender differences are concerned, women were the most frequent visitors of art, ethnography and natural sciences museums, while the majority of male respondents prefer to visit history, natural sciences or art museums. As far as the age categories and museum-type related visiting are concerned, most of the visitors of history, art, natural sciences, and technical museums were people aged 15-36, while the majority of ethnography museums' visitors were $36-57$ years old.

The role that a museum assumes to play within a society depends on the managers' vision and policy, on its activity profile and on the public it addresses. This role may be assumed through official documents, as specific objectives and activities, or it may be deciphered from the concrete activities which the museum carries out within a certain community or within the society on the whole. We shall hereunder try to analyse the role which Bucharest's museums officially or non-officially assume within the local community and at national level.

\section{Dimitrie gusti national village museum}

The analysis of the museum's official website emphasises an official assumption of its main objectives: scientific research, cultural goods collection, heritage management, conservation, restoration and exploitation of the heritage, heritage valorisation, according to the Organisation and Functioning Regulations approved by $\mathrm{OMC}^{1}$ 2702/09.12.2013. As a matter of fact, the crucial importance of these objectives within the activity of the museum is pointed out by the website's sections that address them and by the complexity of the information regarding the museum heritage and educational programmes. From the potential visitors' viewpoint, the website presents all the necessary information to facilitate the access, as well as information regarding the services offered by the museum, except for the foreign visitors, as the English section of the site is incomplete. The component of spending one's spare time in an entertainmenttype manner is well-proportioned within the events organised by the museum. Although the website does not give the public the possibility of taking a virtual tour, the multitude of photos picturing the objectives to visit within the museum helps potential visitors to become familiar to the museum space. As far as the public diversification is concerned, the museum offers free access to children, war veterans, people with disabilities and scholars of the Romanian state, as well as to experts in the field. It is noteworthy that the educational programmes particularly address children, not other categories of public. Yet the museum has not a reflexive attitude and does not promote themes that pertain to the role of the museum as a factor of social change. The conclusion of the virtual foray within the Village Museum's space could be that it is a conservative-type museum that is making efforts to combine tradition with the requirements of a post-modern society.

\section{Grigore antipa national museum of natural history}

From the first moment, the foray into the virtual space of the Museum emphasises the focus on the public within the objectives assumed by the museum's management. The public is invited to discover, to visit and participate-three pillars which support the relation between the museum and its potential or regular visitors. The mission of the museum is stated in an informal language and aims for the collection-based research component and for education through knowledge transfer, as well as at spending one's free time in an agreeable manner. Through this explicit statement of the role that the museum wishes to play within the contemporary Romanian society, through the information presented to the public, through the educational programmes addressing not only children, but also adults,

${ }^{1}$ Order of the Minister of Culture 
through the promotion of a Museum belonging to Everybody, through its facilities for people with special needs, through its temporary exhibitions and the themes of its conferences "At Antipa, behind the closed doors", the museum proves to be a post-modern type museum. The main reasons for this classification are the focus on the public in the museum's discourse, the diversification of the public categories, an inclusive approach for the vulnerable categories, an action towards social change through a reflexive attitude towards the themes of actuality, the promotion of informal and life-long education, the access to information in an interactive and entertaining manner.

The national museum of the romanian peasant-female, higher education, aged 36-57 or 15-35

The museum's mission and the role it wishes to play within the community are stated on the first page of the website, and the message is the promotion of a familiar, friendly space, where the visitor would feel at home, regardless of his/her age and previous experience. This message translates the preoccupation for the public as central objective of the museum, from the viewpoint of the family-like relationship which the museum aims to establish with the visitors. The objects of the museum are important not only because they represent a national heritage with a special identity-value, which must be preserved and protected, but also because they intermediate the museum-public communication. From this point of view, the museum distinguishes itself as a post-modern museum, its conservation and preservation mission being put to the service of transmitting the exhibition message to the visitors. In support for this argument comes the virtual tour, the educational programmes addressing children and adults, leisure spaces, free access for several categories of visitors, approaching actuality themes within the temporary exhibitions and the events it organises

Romania's national history museum-female, postgraduate studies, aged $36-57$ or 58-79

The virtual foray into the analysed museum space emphasises the critical importance given to conservation and research in the museum's discourse over the attention given to the public, even though the museum's role and mission do not appear explicitly in any of the website sections. The information for the public is minimal and refers to the working hours and access fees as well as booking a guide. The educational programmes are scarce and address children in particular. There is no useful information regarding the access to the museums by means of transport, facilities for certain vulnerable groups, possible leisure spaces, and there is no English version for the site. For all these reasons, we draw the conclusion that the public-museum relation is minimal, limited to providing specialised information. This is why we consider that the analysed museum space is a typical example of conservative museum.

The national Art museum-female, higher education, aged 36-57 or 58-79

Even from the start of the virtual visit one can notice a balance between the conservation and restoration component, the educational component and the attention given to the public. As far as the public-care is concerned, useful detailed information is presented with priority, in English inclusively, the events are diversified and address many types of visitors, the virtual tour of the museum is fully functional. The social inclusion dimension is achieved through lower fees for the vulnerable groups and for the events organised for them. The reflexivity of the museum discourse towards themes of actuality is limited, but the promotion of interdisciplinary approaches and the intersection of the museum discourse with other types of artistic discourse stand out. For all these reasons, we draw the conclusion that the analysed museum is a post-modern museum through the role it assumes-though unasserted-within the contemporary Romanian society.

The museum of the city of bucharest-female, higher education, aged 36-57

At the moment of this analysis, the information posted on the museum's website was minimal and referred to the events organised for the Night of the Museums and the public access. This is why we consider that the information is insufficient for the classification of this museum into one of the aforementioned museum-types.

The contemporary art museum-female, postgraduate studies, equal percentages for the ages of 36-57 and 58-79

This museum's role within the Romanian society is asserted right in its title, and the virtual foray confirms its classification into the post-modern type. The prevalent importance of the public, the encouragement of interactivity, social inclusion activities through the promotion of a sensescape-type exhibition space addressing people with special needs, educational programmes addressing children and youth, information in English for foreign visitors, all these come to support the previous assertions. However, we must notice the lack of practical information for the public, regarding the access to the museum or possible leisure spaces.

\section{Conclusion}

In this paper we aimed at following the public-museum relation according to the specificity, role and mission of the latter, as well as to the public's profile. We noticed that the role of the museum within the society was different in certain periods of time, oscillating between a predominant role of preservation/conservation of exhibits and cultural education and a (more recent) role of entertainment/leisure, or even of social inclusion and responsibility. Romanian museums are conforming to this oscillation, and our analysis aimed to emphasising the manner they present themselves to the public and the relationship they wish to establish with the public or the community they are part of. The virtual foray into the museum space emphasised the efforts of the museums to put themselves to the service of the public and to satisfy the visitors' expectations, beyond their mission of preserving and promoting the cultural heritage and cultural education. In time, due to this approach of their relation with the public, the number of visitors - quite small at present - may increase; reaching a level similar to other museums', and the public categories will diversify even more. Through their stated or applied mission, most of the Romanian museums tend to become post-modern museums, at the crossroads between culture and society.

\section{Acknowledgements}

None.

\section{Conflict of interest}

The author declares that there is no conflict of interest. 


\section{References}

1. Negrin Llewellyn. Art and Gastronomy: An analysis of the significance of the new cultural spaces that blur the boundary between art and the food and wine experience. Copenhagen: Socioaesthetcis Conference; 2009. 1-29 p.

2. Ritzer George. Globalizarea nimicului. Cultura consumului și paradoxurile abundenței. București: Humanitas; 2010. 309 p.

3. Baudrillard Jean. La Societe de consommation. Ses mythes ses structures. France: Denoel; 1970. 308 p.

4. Prior Nick. Having One's Tate and Eating It: Transformations of the Museum in a Hypermodern Era. Malden: Blackwell Publishing Ltd; 2003. 213 p.

5. Bourdie Pierre, Darbel Alain. European Art Museums and their Public. Cambridge: Polity Press; 1991. 182 p.
6. Bourdieu Pierre. Distinction. A Social Critique of the Judgement of Taste. Cambridge: Harvard University Press. 1984. 632 p.

7. McClellan Andrew. Art and its Publics. Museum Studies at the Millennium. Malden: Blackwell Publishing Ltd; 2003. 213 p.

8. Rice Danielle. "Museums: Theory, Practice, and Illusion". In McClellan Andrew, editor. Art and its Publics. Museum Studies at the Millennium. Malden: Blackwell Publishing Ltd; 2003. 77-95 p.

9. Weil Stephen. The Museum and the Public. In: Watson Sheila, editor. Museums and their Communities. London: Routledge; 2007. 592 p.

10. Pălici Bogdan. Bucharest Museums: Visiting Practices and Public's Profile" in Croitoru, Carmen and Becuț, Anda. 2014 Cultural Consumption Barometer. Culture between Global and Local. Bucharest: Pro Universitaria; 2014. 274 p. 